\title{
El derecho internacional humanitario en la jurisprudencia de la Corte Interamericana de Derechos Humanos**
}

\section{International Humanitarian Law in the jurisprudence of the Inter-American Court of Human Rights}

SUMARIO

Introducción. I. Fundamentos que justifican la utilización del DIH por la Corte Interamericana en la aplicación de la Convención Americana. 1. Fuentes que han permitido a la Corte Interamericana confirmar la existencia de un conflicto armado que justifique la remisión al DIH. A. El reconocimiento de responsabilidad del Estado y la interpretación de su silencio. B. Los informes de las Comisiones de la Verdad. 2. Fuentes que han permitido a la Corte Interamericana sustentar la competencia rationae materiae que justifique la remisión al DIH. A. Las referencias convencionales para fundamentar la remisión al DIH. B. Las referencias extraconvencionales para fundamentar la remisión al DIH. II. La evolución de las referencias explícitas al DIH en la jurisprudencia de la Corte Interamericana. 1. El DIH como complemento del

Abogada peruana (2005, Pontificia Universidad Católica del Perú); candidata a doctora en Derecho Internacional y Europeo por la Universidad París 1, Panthéon-Sorbonne, Francia; máster en Derechos Humanos (2014, Universidad París X Nanterre La Défense, Francia); diplomada del postítulo en Derechos Humanos y Procesos de Democratización (2007, Centro de Derechos Humanos de la Facultad de Derecho de la Universidad de Chile y The International Center for Transitional Justice), y miembro del Colegio de Abogados de Lima. Consultora independiente en temas de Derecho Internacional de los Derechos Humanos y Derecho Internacional Humanitario, e investigadora del Groupe d'études en droit international et latino-américain de La Sorbonne (GEDILAS-IREDIES). Previamente se desempeñó como abogada en la Corte Interamericana de Derechos Humanos (2008-2011) y como responsable de programa en la Delegación Regional del Comité Internacional de la Cruz Roja (CICR) para Bolivia, Ecuador y Perú (20042008).Contacto: juany.ibanez@gmail.com

El presente artículo es una versión resumida y actualizada de la tesis "Le droit international humanitaire au sein de la jurisprudence contentieuse de la Cour interaméricaine des droits de l'homme", presentada y sustentada públicamente por la autora en octubre de 2014 para la obtención del título de "Master 2 Recherche en droits de l'homme" por la Universidad París X Nanterre La Défense, Francia.

Recibido el 18 de diciembre de 2015, aprobado el 16 de mayo de 2016.

Para citar el artículo: J. M. IBÁÑEz RIVAS, El derecho internacional humanitario en la jurisprudencia de la Corte Interamericana de Derechos Humanos, Derecho del Estado n. ${ }^{\circ} 36$, Universidad Externado de Colombia, enero-junio de 2016, pp. 167-198. Dor: http://dx.doi. org/10.18601/01229893.n36.06. 
contenido y alcance de los derechos y obligaciones reconocidos en la Convención Americana. A. Los derechos humanos convencionales a la luz del DIH. B. Las obligaciones convencionales del Estado a la luz del DIH. 2. El DIH integrado en el razonamiento de la Corte Interamericana. A. Los principios del DIH puestos en escena. B. El DIH incorporado en las medidas de reparación ordenadas por la Corte Interamericana. Conclusión.

\section{RESUMEN}

La convergencia del derecho internacional de los derechos humanos (DIDH) y el derecho internacional humanitario (DIH) ha sido puesta en evidencia en la jurisprudencia de la Corte Interamericana de Derechos Humanos a partir del año 2000. Desde ese momento y hasta la fecha, la Corte se ha remitido explícitamente al DIH en el análisis de ciertos casos vinculados a situaciones de conflicto armado interno. Para ello, la Corte se ha confrontado a la necesidad de verificar que los hechos de los casos concernidos se desarrollan en tales situaciones y, asimismo, ha debido sustentar la razón por la cual sus consideraciones hacen referencia a un marco normativo ajeno al corpus juris interamericano entendido en sentido estricto. La jurisprudencia resultado de dicha práctica demuestra que la Corte Interamericana no sólo ha utilizado el DIH para complementar el contenido y alcance de los derechos humanos y las obligaciones generales de los Estados en casos relacionados a un conflicto armado interno, sino también para integrarlo en su razonamiento más allá de la simple interpretación mediante la remisión a los principios básicos del DIH y en las consecuencias de la declaración de la responsabilidad internacional del Estado. Por tanto, la Corte Interamericana, órgano regional de control de derechos humanos por excelencia, parece haber devenido también un mecanismo indirecto, quizá casi directo, de control del DiH.

PALABRAS CLAVE

Derecho internacional de los derechos humanos, derecho internacional humanitario, corte interamericana de derechos humanos, corpus juris interamericano.

\section{ABSTRACT}

The convergence of International Human Rights Law (IHRL) and International Humanitarian Law (IHL) can be seen in the jurisprudence of the Inter-American Court of Human Rights as of the year 2000. From that time, and until now, the Court has explicitly referred to IHL in its analysis of certain cases linked to situations of internal armed conflict. In that regard, the Court has been confronted by the need to verify that the facts of the relevant cases actually took place in such contexts and, moreover, has had to justify the reasons 
why its considerations refer to a legal framework that is external to the Inter-American corpus juris strictly speaking. The case law that has resulted from this practice demonstrates that the Inter-American Court has relied on IHL to complement the content and scope of human rights and of the general obligations of States in cases related to an internal armed conflict; and to integrate it to its reasoning, beyond mere interpretation, through references to the basic principles of IHL and to the consequences of a declaration of a State's international responsibility. As such, the Inter-American Court, the regional organ par excellence for the monitoring of human rights, appears to have also become an indirect, perhaps even a direct, mechanism for the control of IHL.

\section{KEYWORDS}

International Human Rights Law, International Humanitarian Law, InterAmerican Court of Human Rights, Inter-American corpus juris.

\section{INTRODUCCIÓN}

La convergencia del derecho internacional de los derechos humanos (en adelante, DIDH) y el derecho internacional humanitario (en adelante, DIH) en la protección de la dignidad de la persona humana no es objeto de duda alguna. Sin embargo, la aproximación a dicha protección desde estas dos ramas del derecho internacional público es diferente, dando lugar a importantes divergencias entre una y otra, especialmente en lo que concierne a los mecanismos establecidos para garantizar su aplicación. Los instrumentos convencionales del DIDH comprenden diversos mecanismos internacionales de control ante órganos de protección de los derechos humanos, mientras que el DIH cuenta con mecanismos más limitados, con un nivel de implementación casi inexistente ${ }^{1}$. Ante esta situación, los mecanismos de control del DIDH parecen desempeñar un rol complementario como garantes de la implementación del DIH.

En el marco de los sistemas regionales de derechos humanos, nos concentraremos en el órgano judicial autónomo del Sistema Interamericano de Derechos Humanos (en adelante, Sistema Interamericano), la Corte Interamericana de Derechos Humanos (en adelante, Corte Interamericana o Corte), que ha desarrollado una relación de larga data entre el DiH y la aplicación de la Convención Americana sobre Derechos Humanos (en adelante, Convención Americana, Convención o CADH), sobre todo en el ejercicio de su función contenciosa, poniendo en evidencia diferentes aproximaciones en la remisión a dicho derecho a lo largo de su jurisprudencia.

1 MARMIN, S.. Les organes de contrôle du droit international des droits de l'homme et le droit international humanitaire. RTDH. Año 23, n. ${ }^{\circ} 92,1$ de octubre de 2012, 818-819. 
En las primeras sentencias de la Corte identificamos casos vinculados a situaciones de conflicto armado interno que, no obstante, omiten cualquier remisión expresa al DIH. En dichos casos sólo el "lenguaje" del DIH es utilizado de manera más o menos discreta para presentar los actores del conflicto armado, así como los hechos violatorios de los derechos reconocidos en la Convención Americana en tal contexto. En esa medida, en dicha jurisprudencia, el DIH parece estar presente de manera implícita o "en clave"2.

Será recién en el año 2000, con ocasión del caso Las Palmeras vs. Colombia $^{3}$, que la Comisión Interamericana de Derechos Humanos (en adelante, Comisión Interamericana, Comisión o $\mathrm{CIDH})^{4}$ confrontará por primera vez a la Corte Interamericana con la posibilidad de usar el DIH en el ejercicio de sus competencias ${ }^{5}$. Este caso marcará el inicio de una serie de referencias explícitas al DIH en la jurisprudencia contenciosa de la Corte Interamericana, en particular en casos que conciernen a cuatro Estados parte de la Convención con una historia vinculada al conflicto armado interno, a saber, Colombia, El Salvador, Guatemala y Perú. La Corte postulará así la diferencia entre "aplicar" e "interpretar" el DIH, precisando que si bien no es competente para aplicarlo, sí lo es para interpretar la Convención Americana a la luz del mismo.

En el marco de dicha referencia explícita al DIH a partir del año 2000, es posible identificar aun dos aproximaciones diferentes: una primera a partir de la cual la Corte utiliza el DIH como complemento del contenido y alcance de los derechos humanos y de las obligaciones generales de los Estados reconocidos en la Convención, y una segunda en la que el DIH es verdadera-

2 Flauss, J.-F. Le droit international humanitaire devant les instances de contrôle des conventions européenne et interaméricaine de droits de l'homme. En Flauss, J.-F. (dir.), Les nouvelles frontières du droit international humanitaire. Actes du colloque du 12 avril 2002 organisé par l'Institut d'études de droit international de l'Université de Lausanne. Bruxelles: Némésis-Bruylant, 2003, 124.

3 El caso se refiere a una operación dirigida por miembros de la Policía Nacional y el Ejército de Colombia en el marco de la cual 7 personas fueron víctimas de ejecuciones extrajudiciales. Corte IDH. Caso Las Palmeras vs. Colombia. Excepciones Preliminares. Sentencia de 4 de febrero de 2000. Serie C n. ${ }^{\circ}$ 67; Caso Las Palmeras vs. Colombia. Fondo. Sentencia de 6 de diciembre de 2001. Serie C n. ${ }^{\circ}$ 90, y Caso Las Palmeras vs. Colombia. Reparaciones y Costas. Sentencia de 26 de noviembre de 2002 . Serie C n. ${ }^{\circ} 96$.

4 Al respecto cabe destacar que, desde 1997, la Comisión Interamericana afirmaba su competencia para aplicar directamente el DIH. CIDH, Arturo Ribón Ávila, Colombia, Caso 11.142, Informe n. ${ }^{\circ}$ 26/97 de 30 de septiembre de 1997, y Juan Carlos Abella, Argentina, Caso 11.137, Informe n. ${ }^{\circ}$ 55/97 de 18 de noviembre de 1997.

5 En su demanda, la ciDH solicitó a la Corte declarar que Colombia había violado el derecho a la vida (art. 4 CADH) y el artículo 3 común a los Convenios de Ginebra de 1949. Sin embargo, en dicha oportunidad la Corte resaltó que la Convención sólo le había atribuido competencia "para determinar la compatibilidad de los actos o de las normas de los Estados con la propia Convención, y no con los Convenios de Ginebra de 1949". En consecuencia, contrariamente a la posición de la CIDH, la Corte rechazó la posibilidad de aplicar el DIH y admitió la excepción preliminar rationae materiae opuesta por el Estado. Corte IDH, Caso Las Palmeras vs. Colombia. Excepciones Preliminares, cit., párr. 33. 
mente integrado en el razonamiento de la Corte y en las consecuencias de la declaración de la responsabilidad internacional del Estado, a tal punto que el rol de dicho derecho parece ir más allá de la simple interpretación.

En cualquier caso, las referencias implícitas y explícitas al DIH no necesariamente responden a etapas de "preclusión" en la jurisprudencia de la Corte. Después del año 2000, cuando la Corte comenzó a referirse explícitamente al DIH, y hasta hoy, existen sentencias de casos vinculados a conflictos armados que no han hecho ninguna mención expresa al DiH. Asimismo, a pesar de la jurisprudencia más audaz de la Corte, que parece ir más allá de la remisión al DIH en términos de interpretación, las referencias al DIH como complemento del contenido y alcance de los derechos humanos y las obligaciones estatales continúan desarrollándose paralelamente. Por tanto, no hay una regla respecto a los criterios que determinan el uso del DIH por la Corte, aunque sí es claro que dicho uso constituye un hecho real y -nos parece- inevitable que, con el paso del tiempo, ha demostrado no tener punto de retorno ${ }^{6}$.

En el presente artículo nos enfocaremos en el análisis del uso explícito del DIH por la Corte Interamericana, a partir de la identificación de los fundamentos que lo justifican (I) y del estudio de la evolución de la remisión a dicho derecho en su jurisprudencia (II).

\section{FUNDAMENTOS QUE JUSTIFICAN LA UTILIZACIÓN DEL DIH POR LA CORTE INTERAMERICANA EN LA APLICACIÓN DE LA CONVENCIÓN AMERICANA}

En la medida que la Corte Interamericana es un órgano de control del DIDH con competencias específicas definidas en la Convención Americana, el uso de normas ajenas al corpus juris interamericano, incluidas las del DIH, exige justificaciones más allá de la loable vocación de promover una mayor protección de los derechos humanos. Dado que la remisión al DiH es solamente pertinente en el marco de un conflicto armado, la Corte se ha confrontado a la necesidad de verificar que los hechos de los casos concernidos se desarro-

6 Cabe señalar que, en lo que concierne al Sistema Europeo de Derechos Humanos, también existen diferentes aproximaciones al DIH en la jurisprudencia del Tribunal Europeo de Derechos Humanos (TEDH). Pese a que desde el inicio de sus actividades el TEDH ha estado confrontado a casos vinculados a conflictos armados, tanto de carácter internacional como no internacional, ha evitado referirse explícitamente al DIH. Será mucho más tarde, a partir de finales de los años 2000, que el TEDH comenzará a referirse explícitamente al DIH de manera progresiva, llegando a definir su posición sobre la interacción entre el DIDH y el DIH en tiempo de conflicto armado en el año 2014. Al respecto, ver Costa, J.-P. y O’Boyle, M. The European Court of Human Rights and international humanitarian law. En La Convention européenne des droits de l'homme, un instrument vivant / The European Convention on Human Rights a Living Instrument, Mélanges en l'honneur de / Essays in Honour of Christos L. Rozakis. Bruxelles: Bruylant, 2011, 107-129 y HERVIEU, N. La jurisprudence européenne sur les opérations militaires à l'épreuve du feu. La Revue des droits de l’homme [en línea], Actualités Droits-Libertés, <http://revdh.revues. org/890> (consultada el 15 de diciembre de 2015). 
llan en tal contexto (1). Asimismo, el uso del DIH ha exigido la identificación de los fundamentos que sustentan la competencia rationae materiae de la Corte para remitirse a un marco normativo ajeno al referido corpus juris interamericano, entendido en sentido estricto (2).

\section{Fuentes que han permitido a la Corte Interamericana confirmar la existencia de un conflicto armado que justifique la remisión al DIH}

La historia del continente americano da cuenta de diferentes situaciones de interrupción de la vida democrática en los Estados debido, inter alia, a la imposición de gobiernos dictatoriales o al estallido de conflictos armados. Estas situaciones han marcado el contexto de la región incluso pese al establecimiento y funcionamiento del Sistema Interamericano ${ }^{7}$. Así, la existencia de conflictos armados internos en algunos Estados parte de la Convención ha sido un hecho histórico innegable.

Sin embargo, para la Corte, como órgano jurisdiccional de derechos humanos, es imprescindible que la existencia de un conflicto armado interno como contexto de un caso sea un hecho debidamente probado ${ }^{8}$. Para ello, en diferentes fuentes del expediente de los casos concernidos, la Corte Interamericana ha encontrado la respuesta no sólo para confirmar la existencia de un conflicto armado interno, sino también para identificar si a nivel interno dicho conflicto fue regulado únicamente por el artículo 3 común a los cuatro Convenios de Ginebra de 1949 (en adelante, artículo 3 común) o también por el Protocolo II adicional a los Convenios de Ginebra de 1949 relativo a la protección de las víctimas de los conflictos armados sin carácter internacional de 1977 (en adelante, PA II) ${ }^{9}$.

7 Ver Burgorgue-Larsen, L. y Úbeda de Torres, A. War in the Jurisprudence of the Inter-American Court of Human Rights. HRQ. Vol. 33(1), February 2011, 148-174.

8 A diferencia del TEDH, hasta la fecha, la Corte Interamericana no ha tenido la oportunidad de analizar a la luz del DIH casos vinculados a un conflicto armado de carácter internacional, entendido este en los términos del artículo 2 común a los cuatro Convenios de Ginebra de 1949 y del artículo 1.4 PA I. Sin embargo, cabe destacar que actualmente se encuentra en trámite ante la Corte el caso Vásquez Durand y familiares vs. Ecuador, relacionado con la presunta desaparición forzada de Jorge Vásquez Durand, comerciante de nacionalidad peruana, en el contexto del conflicto del Alto Cenepa entre Ecuador y Perú. Corte IDH. Casos en Etapa de Fondo (Pendientes de emitirse sentencia), <http://www.corteidh.or.cr/docs/tramite/vasquez_durand_y_familiares. pdf $>$, (consultada el 15 de diciembre de 2015).

9 La posibilidad de remisión al PA II se ha visto reforzada por el hecho de que los cuatro Estados parte concernidos han ratificado dicho tratado: Colombia el 1 de septiembre de 1993, Guatemala el 19 de octubre de 1987, El Salvador el 23 de noviembre de 1978, y Perú el 14 de julio de 1989. 


\section{A. El reconocimiento de responsabilidad del Estado y la interpretación de su silencio}

En ciertos casos, el contexto de conflicto armado interno ha quedado establecido como hecho probado o no controvertido a partir del propio reconocimiento de responsabilidad del Estado, con independencia de que este haya reconocido la existencia del conflicto armado como tal ${ }^{10}$. Al respecto, el artículo 62 del Reglamento de la Corte (Reconocimiento) ${ }^{11}$ establece que si el Estado demandado comunica a la Corte "su aceptación de los hechos o su allanamiento total o parcial a las pretensiones que constan en el sometimiento del caso o en el escrito de las presuntas víctimas o sus representantes, la Corte, oído el parecer de los demás intervinientes en el proceso, resolverá, en el momento procesal oportuno, sobre su procedencia y sus efectos jurídicos". De acuerdo con el artículo 64 del mismo Reglamento (Prosecución del examen del caso), aun en dicho supuesto de reconocimiento, "[1]a Corte, teniendo en cuenta las responsabilidades que le incumben de proteger los derechos humanos, podrá decidir que prosiga el examen del caso".

Por otro lado, según el artículo 41.3 del Reglamento de la Corte (Contestación del Estado), esta puede considerar como aceptados "aquellos hechos que no hayan sido expresamente negados y las pretensiones que no hayan sido expresamente controvertidas", "sin que ello signifique que los tendrá por aceptados automáticamente en todos los casos en donde no existiere oposición de una parte al respecto, y sin que exista una valoración de las circunstancias particulares del caso y del acervo probatorio existente". Según la jurisprudencia de la Corte, el silencio del Estado demandado o su contestación elusiva o ambigua "pueden interpretarse como aceptación de los hechos del Informe de Fondo, mientras lo contrario no aparezca de los autos o no resulte de la convicción judicial" ${ }^{12}$.

$10 \mathrm{Al}$ respecto, cabe recordar que la existencia de un conflicto armado interno "dependerá de la presencia de una serie de elementos, toda vez que se trata de una situación de hecho y no de una calificación jurídica, como podría ser la antigua beligerancia”: SALMón, E. Introducción al derecho internacional humanitario ( 3 . $^{\text {}}$ ed.), Lima, IDEHPUCP/CICR, 2012, 130. A mayor abundamiento, y pese a que no existe una definición normativa y única de conflicto armado interno, la doctrina y la jurisprudencia han intentado una aproximación a la misma a partir de la descripción de los elementos que lo caracterizan, a saber, "a) las partes en conflicto no son Estado[s]; b) los enfrentamientos armados se realizan en el territorio de un Estado; c) [las] hostilidades abiertas deben tener un mínimo de organización; y d) los enfrentamientos armados deben tener cierta intensidad": SALMÓN, ob. cit., 130-131.

11 Aprobado por la Corte en su Lxxxv Período Ordinario de Sesiones celebrado del 16 al 28 de noviembre de 2009.

12 Corte idH. Caso Velásquez, Rodríguez vs. Honduras. Fondo. Sentencia de 29 de julio de 1988. Serie C n. ${ }^{\circ}$ 4, párr. 138, y Caso Rodríguez Vera y otros (Desaparecidos del Palacio de Justicia) vs. Colombia. Excepciones Preliminares, Fondo, Reparaciones y Costas. Sentencia de 14 de noviembre de 2014. Serie C n. ${ }^{\circ} 287$, párr. 82. 
Así, en lo que concierne a Colombia, sobre la base de la interpretación del silencio y del reconocimiento parcial de responsabilidad internacional del Estado en el análisis de las sentencias en los casos Las Palmeras ${ }^{13}$, Masacre de Mapiripán ${ }^{14}$, Masacres de Ituango ${ }^{15}$, Masacre de Santo Domin$\mathrm{go}^{16}$, Comunidades Afrodescendientes Desplazadas de la Cuenca del Río Cacarica (Operación Génesis) ${ }^{17}$, y Rodríguez Vera y otros (Desaparecidos del Palacio de Justicia) ${ }^{18}$ es posible afirmar que la Corte ha asumido, sin la más mínima duda, que un conflicto armado interno tiene lugar en dicho Estado, en el curso del cual se han desarrollado los hechos concernidos. De esta manera, la Corte se ha referido al origen y a la evolución del conflicto armado en Colombia, poniendo en evidencia los diferentes actores estatales y no estatales de las hostilidades.

Por otro lado, en lo que atañe al régimen aplicable al conflicto armado interno colombiano, la decisión C-225 del 18 de mayo de 1995 de la Corte Constitucional de Colombia sobre la constitucionalidad del PA II ha resultado de la mayor importancia. Según esta decisión, citada por la Corte Interamericana en los casos colombianos, "los requisitos de aplicabilidad del artículo 1. ${ }^{\circ}$ [del PA II] son exigencias máximas que pueden ser renunciadas por los Estados, ya que el Protocolo II es un desarrollo y complemento del artículo 3. común". Sin embargo, en la medida que la Constitución colombiana establece claramente que en todo caso se respetarán las reglas del DIH, la Corte Constitucional de Colombia ha concluido que "conforme al mandato constitucional, el [DIH], incluyendo obviamente el Protocolo II, se aplica en

13 Corte IDH. Caso Las Palmeras vs. Colombia, cit.

14 El caso se refiere a la muerte, lesiones y abusos cometidos contra pobladores de la localidad de Mapiripán, por parte de agentes paramilitares. Corte IDH. Caso de la "Masacre de Mapiripán” vs. Colombia. Excepciones Preliminares. Sentencia de 7 de marzo de 2005. Serie C n. ${ }^{\circ} 122$, y Caso de la "Masacre de Mapiripán" vs. Colombia. Fondo y Reparaciones. Sentencia de 15 de septiembre de 2005. Serie $\mathrm{C} n{ }^{\circ}{ }^{\circ} 134$.

15 El caso se refiere a actos de tortura y asesinato de pobladores en el municipio de Ituango, cometidos por grupos paramilitares. Corte IDH. Caso de las Masacres de Ituango vs. Colombia. Sentencia de 1 de julio de 2006. Serie C n. ${ }^{\circ} 148$.

16 El caso se refiere al bombardeo y ametrallamiento del caserío de Santo Domingo por parte de la Fuerza Aérea Colombiana, que ocasionó la muerte, lesiones y desplazamiento forzado de numerosas personas. Corte IDH. Caso Masacre de Santo Domingo vs. Colombia. Excepciones Preliminares, Fondo y Reparaciones. Sentencia de 30 de noviembre de 2012. Serie C n. 259.

17 El caso se refiere a una operación militar contrainsurgente sobre el territorio de las comunidades afrodescendientes de la cuenca del río Cacarica, que ocasionó una muerte y el desplazamiento forzado de alrededor de 3.500 personas. Corte IDH. Caso de las Comunidades Afrodescendientes Desplazadas de la Cuenca del Río Cacarica (Operación Génesis) vs. Colombia. Excepciones Preliminares, Fondo, Reparaciones y Costas. Sentencia de 20 de noviembre de 2013. Serie $\mathrm{C} \mathrm{n} .^{\circ} 270$.

18 El caso se refiere a la desaparición forzada, ejecución extrajudicial, detención y tortura de personas en los eventos conocidos como la "toma y retoma" del Palacio de Justicia, en la ciudad de Bogotá. Corte IDH. Caso Rodríguez Vera y otros (Desaparecidos del Palacio de Justicia) vs. Colombia, cit. 
Colombia en todo caso, sin que sea necesario estudiar si el enfrentamiento alcanza los niveles de intensidad exigidos por el [referido] artículo 1. ${ }^{\circ 19}$.

\section{B. Los informes de las Comisiones de la Verdad ${ }^{20}$}

La Corte Interamericana ha declarado abiertamente que otorga "especial valor a los informes de Comisiones de la Verdad o de Esclarecimiento Histórico como pruebas relevantes en la determinación de los hechos y de la responsabilidad internacional de los Estados en diversos casos que han sido sometidos a su jurisdicción" 21 . No obstante ello, en jurisprudencia reciente, la Corte se ha permitido precisar que el establecimiento de un contexto, con base en un informe de una Comisión de la Verdad, "no [la] exime [...] de realizar una valoración del conjunto del acervo probatorio, de acuerdo con las reglas de la lógica y con base en la experiencia, sin que deba sujetarse a reglas de prueba tasada" 22 .

En lo que concierne a Guatemala, en los casos Bámaca Velásquez ${ }^{23}, \mathrm{Ma}$ sacre de las Dos Erres ${ }^{24}$ y Gudiel Álvarez y otros (Diario Militar) ${ }^{25}$, además

19 Corte Constitucional de Colombia, Sentencia C-225 del 18 de mayo de 1995, revisión constitucional del "Protocolo adicional a los Convenios de Ginebra del 12 de agosto de 1949, relativo a la protección de las víctimas de los conflictos armados sin carácter internacional (Protocolo II)", hecho en Ginebra el 8 de junio de 1977, y de la Ley 171 del 16 de diciembre de 1994, por medio de la cual se aprueba dicho Protocolo; <http://www.corteconstitucional.gov. co/relatoria/1995/c-225-95 htm>, (consultada el 15 de diciembre de 2015).

20 En cuanto a Colombia, la Corte Interamericana se ha remitido recientemente al informe de una Comisión de la Verdad en el caso de los Desaparecidos del Palacio de Justicia. Dicha Comisión fue creada en agosto de 2005 por decisión de la Corte Suprema de Justicia, con la finalidad de que emitiera un informe que se constituyera en un punto de obligada referencia para saber lo que realmente sucedió durante la toma y retoma del Palacio de Justicia. La Comisión de la Verdad emitió su informe final en el 2010.

21 Corte IDH. Caso Myrna Mack Chang vs. Guatemala. Fondo, Reparaciones y Costas. Sentencia de 25 de noviembre de 2003. Serie C n. ${ }^{\circ}$ 101, párrs. 131 y 134; Caso Zambrano Vélez. y otros vs. Ecuador. Fondo, Reparaciones y Costas. Sentencia de 4 de julio de 2007. Serie C n. 166, párr. 128, y Caso Radilla Pacheco vs. México. Excepciones Preliminares, Fondo, Reparaciones y Costas. Sentencia de 23 de Noviembre de 2009. Serie C n. . 209, párr. 179.

22 Corte idH. Caso J. vs. Perú. Excepción Preliminar, Fondo, Reparaciones y Costas. Sentencia de 27 de noviembre de 2013. Serie C n. ${ }^{\circ} 275$, párr. 55, y Caso Rodríguez Vera y otros (Desaparecidos del Palacio de Justicia) vs. Colombia, cit., párr. 88.

23 El caso se refiere a la desaparición forzada de un miembro de un grupo alzado en armas, como consecuencia de un enfrentamiento entre el ejército y la guerrilla. Corte IDH. Caso Bámaca Velásquez vs. Guatemala. Fondo. Sentencia de 25 de noviembre de 2000 . Serie C n. ${ }^{\circ} 70$, y Caso Bámaca Velásquez vs. Guatemala. Reparaciones y Costas. Sentencia de 22 de febrero de 2002. Serie C n. ${ }^{\circ} 91$.

24 El caso se refiere a actos de asesinato, tortura, violación sexual, entre otros, cometidos por agentes militares en perjuicio de numerosas personas habitantes del parcelamiento de Las Erres. Corte IDH. Caso De la Masacre de las Dos Erres vs. Guatemala. Excepción Preliminar, Fondo, Reparaciones y Costas. Sentencia de 24 de noviembre de 2009. Serie C n. ${ }^{\circ} 211$.

25 El caso se refiere a la desaparición forzada de 26 personas, la ejecución extrajudicial de una, y los actos de tortura en perjuicio de una niña, por parte de agentes militares. Corte IDH. 
del reconocimiento de responsabilidad del Estado para la confirmación del contexto de conflicto armado, la Corte ha realizado un reenvío a los informes de las dos Comisiones de la Verdad instituidas en el país en el escenario postconflicto armado, a saber, el Informe "Guatemala Memoria del Silencio"26, de la Comisión para el Esclarecimiento Histórico de las Violaciones a los Derechos Humanos y los Hechos de Violencia que han causado sufrimientos a la Población Guatemalteca (en adelante, Comisión para el Esclarecimiento Histórico), y el Informe "Guatemala: Nunca Más”, del Proyecto Interdiocesano de Recuperación de la Memoria Histórica ${ }^{27}$. A partir de esos dos informes, en los casos guatemaltecos concernidos, ha quedado probado que entre 1962 y 1996 hubo un conflicto armado interno que enfrentó a grupos alzados en armas con las fuerzas armadas del Estado.

De acuerdo al Informe de la Comisión para el Esclarecimiento Histórico, aunque el PA II haya sido ratificado por Guatemala "en un momento bastante tardío del enfrentamiento armado", y pese al hecho de que "el Gobierno siempre ha[ya] negado su aplicabilidad", aquel fue considerado "como parte de su marco jurídico, debido a que buena parte de las reglas contenidas en dicho Protocolo Adicional forman parte del derecho consuetudinario internacional" ${ }^{28}$. Así, la Comisión para el Esclarecimiento Histórico concluyó que las disposiciones del PA II "deb[ían] ser considerad[a]s como un marco de referencia válido y relevante" 29 .

Respecto a El Salvador, en las sentencias de los casos Hermanas Serrano Cruz $^{30}$, Contreras y otros $^{31}$, Masacres de El Mozote y lugares aledaños ${ }^{32} \mathrm{y}$

Caso Gudiel Álvarez y otros ("Diario Militar") vs. Guatemala. Fondo, Reparaciones y Costas. Sentencia de 20 noviembre de 2012 Serie C n. ${ }^{\circ} 253$.

26 Oficina de Servicios para Proyectos de las Naciones Unidas (UNOPS), Informe final de la Comisión para el Esclarecimiento Histórico "Guatemala Memoria del Silencio", Guatemala, 1999.

27 Oficina de Derechos Humanos del Arzobispado de Guatemala (ODHAG), Informe Final del Proyecto Interdiocesano de Recuperación de la Memoria Histórica "Guatemala : Nunca Más", 1998.

28 Informe de la Comisión para el Esclarecimiento Histórico, cit., párr. 74.

29 Ibíd., párr. 1685.

30 El caso se refiere a la desaparición forzada de dos hermanas detenidas por las Fuerzas Armadas de El Salvador en el marco de una operación militar. Corte IDH. Caso de las Hermanas Serrano Cruz vs. El Salvador. Excepciones Preliminares. Sentencia de 23 de noviembre de 2004. Serie C n. ${ }^{\circ} 118$, y Caso de las Hermanas Serrano Cruz vs. El Salvador. Fondo, Reparaciones y Costas. Sentencia de 1 de marzo de 2005. Serie C n. 120.

31 El caso se refiere a la desaparición forzada de niños y niñas ocurrida entre los años 1981 y 1983, por parte de miembros de diferentes cuerpos militares de El Salvador. Corte IDH. Caso Contreras y otros vs. El Salvador. Fondo, Reparaciones y Costas. Sentencia de 31 de agosto de 2011. Serie C n. ${ }^{\circ} 232$.

32 El caso se refiere a un operativo militar, en siete localidades del norte del Departamento de Morazán, que habría ocasionado la muerte de un millar de personas. Corte IDH. Caso Masacres de El Mozote y lugares aledaños vs. El Salvador. Fondo, Reparaciones y Costas. Sentencia de 25 de octubre de 2012. Serie $\mathrm{C} \mathrm{n} .^{\circ} 252$. 
Rochac Hernández y otros ${ }^{33}$, además del reconocimiento de responsabilidad internacional del Estado, la Corte ha considerado el informe de una Comisión de la Verdad para fundamentar la existencia de un conflicto armado en el país. En el caso salvadoreño se trata del Informe de la Comisión de la Verdad para El Salvador, titulado "De la locura a la esperanza, La guerra de 12 años en El Salvador" ${ }^{4}$, leído conjuntamente con los Acuerdos de Paz de El Salvador firmados con el auspicio de la Organización de las Naciones Unidas (ONU) ${ }^{35}$. En ese marco, ha quedado probado que desde 1980 y hasta 1991 El Salvador atravesó un conflicto armado interno que enfrentó al Frente Farabundo Martí para la Liberación Nacional (FMLN) y a las fuerzas armadas del Estado.

El Informe de la Comisión de la Verdad para El Salvador confirmó que el conflicto armado salvadoreño "llenó los requisitos" exigidos para la aplicación del artículo 3 común y el PA II, y que en esa medida dichas disposiciones eran "jurídicamente vinculantes tanto para el gobierno como para las fuerzas insurgentes". A modo de precisión, la Comisión de la Verdad para El Salvador señaló que el FMLN "sostuvo oficialmente que tenía determinados territorios bajo su control y efectivamente ejerció ese control", justificando así la pertinencia del PA II como "derecho aplicable" para el análisis que la Comisión realizó en su informe ${ }^{36}$.

En cuanto a Perú, las sentencias en los casos De La Cruz Flores ${ }^{37}$, Osorio Rivera y familiares ${ }^{38}, J .^{39}$, Espinoza Gonzáles ${ }^{40}$ y Cruz Sánchez y otros ${ }^{41}$ se

33 El caso se refiere a las desapariciones forzadas de niños y niñas entre 1980 y 1982 como consecuencia de diferentes operaciones militares dispuestas por el Estado. Corte IDH. Caso Rochac Hernández y otros vs. El Salvador. Fondo, Reparaciones y Costas. Sentencia de 14 de octubre de 2014. Serie C n. ${ }^{\circ} 285$.

34 Comisión de la Verdad para El Salvador, Informe "De la locura a la esperanza, La guerra de 12 años en El Salvador". Nueva York: San Salvador, 1992-1993.

35 ONU, Acuerdos de El Salvador: en el camino a la paz, 1992, <http://www.pnud.org. sv/2007/content/view/56/102/>, (consultada el 15 de diciembre de 2015).

36 Informe de la Comisión de la Verdad para El Salvador, cit., 11-12.

37 El caso se refiere a la detención arbitraria de una profesional de la salud que habría brindado cuidados médicos a miembros de un grupo alzado en armas, y su condena por el delito de terrorismo sin un debido proceso. Corte IDH. Caso De la Cruz Flores vs. Perú. Fondo, Reparaciones y Costas. Sentencia de 18 de noviembre de 2004. Serie C n. ${ }^{\circ} 115$.

38 El caso se refiere a la desaparición forzada de Jeremías Osorio Rivera, detenido por una patrulla del ejército peruano. Corte IDH. Caso Osorio Rivera y Familiares vs. Perú. Excepciones Preliminares, Fondo, Reparaciones y Costas. Sentencia de 26 de noviembre de 2013. Serie C n. ${ }^{\circ}$ 274.

39 El caso se refiere a la detención, enjuiciamiento y extradición de la señora J. por la supuesta comisión de los delitos de apología y terrorismo. Corte IDH. Caso J. vs. Perú, cit.

40 El caso se refiere a la detención ilegal y arbitraria y los actos de tortura cometidos por agentes del Estado contra Gladys Carol Espinoza Gonzales, en el marco de una investigación por el delito de traición a la patria y terrorismo. Corte IDH. Caso Espinoza Gonzales vs. Perú. Excepciones Preliminares, Fondo, Reparaciones y Costas. Sentencia de 20 de noviembre de 2014. Serie C n. ${ }^{\circ} 289$.

41 El caso se refiere a la ejecución extrajudicial de un miembro de un grupo alzado en armas por parte de las fuerzas del Estado, en el marco de una operación de rescate de los rehenes 
han remitido principalmente al Informe de la Comisión de la Verdad y Reconciliación (en adelante, CVR) ${ }^{42}$ y a los casos precedentes referidos a Perú, en tanto que elementos de prueba de la existencia de un conflicto armado interno en el país. De acuerdo con la Corte, dicho informe "es un referente importante, pues brinda una visión integral del conflicto armado en el Perú" 43. De esta manera, citando el Informe de la CVR, la Corte ha confirmado que desde el inicio de la década de 1980 y hasta el final del año 2000, Perú vivió un conflicto armado entre, de un lado, los agentes de la policía y las fuerzas armadas, y del otro, los grupos alzados en armas "Sendero Luminoso" y "Movimiento Revolucionario Túpac Amaru".

Igualmente, el Informe de la CVR ofreció algunas referencias respecto al régimen del DIH aplicable al conflicto armado interno que tuvo lugar en el país durante dos décadas. La CVR declaró que los hechos examinados en su informe solamente se explicaban "por la existencia de un conflicto armado interno regido sin duda alguna por el artículo 3 común" 44 . Si bien la CVR indicó expresamente que no era el órgano que debía decidir si el conflicto armado peruano cumplía los requisitos exigidos para la aplicación del PA II, concluyó que el artículo 3 común constituía "el marco normativo adecuado para la determinación del núcleo inderogable de derechos vigentes", aunque ello no constituyera "en modo alguno obstáculo para aplicar las disposiciones del Protocolo II, en lo que resulte compatible y pertinente" 45 .

Por todo lo expuesto, es claro que en los casos en los que la Corte Interamericana ha hecho referencia explícita al DIH, la existencia de un conflicto armado, presupuesto esencial para la remisión a dicho cuerpo normativo, no ha sido determinada directamente por la Corte. Para establecer como hecho probado dicho contexto, la Corte se ha basado en el reconocimiento de responsabilidad internacional del Estado, la interpretación del silencio del mismo y los informes de Comisiones de la Verdad. Tales fuentes también han permitido que la Corte conozca el régimen del DiH aplicado al análisis del conflicto armado interno concernido y que, en esa medida, haga reenvío indistinto a las normas del artículo 3 común y del PA II en sus consideraciones.

\section{Fuentes que han permitido a la Corte Interamericana sustentar la competencia rationae materiae que justifique la remisión al DIH}

Ni el preámbulo ni los diferentes artículos de la Convención Americana hacen referencia explícita al DIH. Sin embargo, existen ciertos artículos en

tomados por dicho grupo. Corte IDH. Caso Cruz Sánchez y otros vs. Perú. Excepciones Preliminares, Fondo, Reparaciones y Costas. Sentencia de 17 de abril de 2015. Serie C n. 292.

42 CVR, Informe Final de la CVR, Lima, CVR, 2003, 11-31.

43 Corte IDH. Caso Cruz Sánchez y otros vs. Perú, cit., párr. 139.

44 Informe de la CVR, cit., 204.

45 Ibíd., 205. 
el texto de la Convención cuya interpretación ha dado a la Corte elementos para sustentar la pertinencia del reenvío al DIH en su jurisprudencia. Adicionalmente, puesta en cuestión por los Estados sobre su competencia rationae materiae para utilizar el DIH, la Corte Interamericana se ha valido también de referencias extraconvencionales para justificar la lectura convencional a la luz de dicha rama del derecho.

\section{A. Las referencias convencionales para fundamentar la remisión al DIH}

En cuanto a las referencias convencionales que han permitido sustentar el uso del DIH, cabe destacar tres normas específicas de la Convención Americana, a saber, los artículos 27, 29 y 64 .

De conformidad con el artículo 29 de la Convención, sobre "Normas de Interpretación", y el artículo 64, que regula la competencia consultiva de la Corte, esta ha establecido que la Convención puede ser interpretada en relación con otros instrumentos internacionales ${ }^{46}$. La Corte ha señalado que cuando un Estado es parte de la Convención y ha aceptado su competencia contenciosa, ella puede examinar la compatibilidad de la conducta de dicho Estado o de una norma del derecho interno con las obligaciones y derechos contenidos en dicha Convención, interpretada a la luz de otros tratados ${ }^{47}$. A partir de ello, la Corte ha declarado que existe "equivalencia" entre el contenido del artículo 3 común y el de las disposiciones de la Convención y de otros instrumentos internacionales sobre derechos humanos inderogables, y que "las disposiciones relevantes de los Convenios de Ginebra pueden ser tomad[a]s en cuenta como elementos de interpretación de la propia Convención Americana". Esta precisión ha constituido el punto de partida para que la Corte remarque la diferencia conceptual entre "aplicación" e "interpretación", destacando que pese a que no es competente para aplicar el DIH en sus casos, sí lo es para utilizarlo como instrumento de interpretación de la Convención Americana ${ }^{48}$.

De esta manera, sobre la base de la jurisprudencia de su primera opinión consultiva de $1982^{[49]}$, la Corte se ha reservado "un droit de regard" ${ }^{50}$ sobre el respeto de las obligaciones del DIH por un Estado parte de la Convención,

46 Corte IDH. Caso Rodríguez, Vera y otros (Desaparecidos del Palacio de Justicia) vs. Colombia, cit., párr. 39.

47 Corte IDH. Caso Las Palmeras vs. Colombia. Excepciones Preliminares, cit., párr. 32 y Caso Rodríguez Vera y otros (Desaparecidos del Palacio de Justicia) vs. Colombia, cit., párr. 39.

48 Corte IDH. Caso Bámaca Velásquez vs. Guatemala. Fondo, cit., párr. 209, y Caso de la Masacre de Mapiripán vs. Colombia. Fondo y Reparaciones, cit., párr. 114.

49 Corte IDH. "Otros Tratados" Objeto de la Función Consultiva de la Corte (art. 64 Convención Americana sobre Derechos Humanos). Opinión Consultiva OC-1/82 del 24 de septiembre de 1982. Serie A n. ${ }^{\circ} 1$.

50 MARMIN, cit., 825. 
aun cuando no pueda, en principio, derivar consecuencias jurídicas de ello. La Corte ha precisado así que si bien "carece de competencia para declarar que un Estado es internacionalmente responsable por la violación de tratados internacionales que no le atribuyen dicha competencia, $[\ldots]$ puede observar que ciertos actos u omisiones que violan los derechos humanos de acuerdo con los tratados que le compete aplicar infringen también otros instrumentos internacionales de protección de la persona humana, como los Convenios de Ginebra de 1949 y, en particular, el artículo 3 común" ${ }^{51}$.

Por otro lado, en lo que atañe al artículo 27, sobre "Suspensión de Garantías", si bien la Corte no se ha referido al mismo en todos los casos vinculados a situaciones de conflicto armado interno, entre otras cosas, por no haber sido cuestionada una alegada suspensión de garantías, ello no representa un obstáculo para destacar su relevancia como fuente convencional que justifica la remisión al DiH en la jurisprudencia de la Corte. En cualquier caso, su importancia radica en el hecho de ser el único artículo de la Convención Americana que menciona a "la guerra" como marco de aplicación del tratado.

Sobre el particular, la Corte ha señalado que si bien "el Estado tiene el derecho y la obligación de garantizar su seguridad y mantener el orden público, su poder no es ilimitado, pues tiene el deber, en todo momento, de aplicar procedimientos conformes a derecho y respetuosos de los derechos fundamentales a todo individuo que se encuentre bajo su jurisdicción" ${ }^{52}$. Así, de acuerdo con la Corte, "el artículo 27.1 de la Convención permite la suspensión de las obligaciones que establece, 'en la medida y por el tiempo estrictamente limitados a las exigencias de la situación' de que se trate. Las disposiciones que se adopten no deben violar otras obligaciones internacionales del Estado Parte, ni deben entrañar discriminación alguna $[\ldots]^{53}$. Ello implica entonces, que tal prerrogativa debe ser ejercida e interpretada, al tenor además, de lo previsto en el artículo 29.a) de la Convención, como excepcional y en términos restrictivos". Por su parte, el artículo 27.2 precisa cuáles son los derechos de la Convención constitutivos del núcleo inderogable, es decir, no susceptibles de suspensión en caso de guerra, de peligro público o de otra emergencia que amenace la independencia o seguridad de un Estado parte ${ }^{54}$. Finalmente, el

51 Corte idH. Caso Bámaca Velásquez vs. Guatemala. Fondo, cit., párr. 208.

52 Corte IDH. Caso Bámaca Velásquez vs. Guatemala. Fondo, op. cit., párr. 174; Caso J. vs. Perú, op. cit., párr. 124, y Caso Espinoza Gonzáles vs. Perú, op. cit., párrs. 117, 119-120.

53 Corte IDH. El hábeas corpus bajo suspensión de garantías (arts. 27.2, 25.1 y 7.6 Convención Americana sobre Derechos Humanos). Opinión Consultiva OC-8/87 del 30 de enero de 1987. Serie A n. ${ }^{\circ}$, párr. 19; Caso J. vs. Perú, op. cit., párr. 139, y Caso Espinoza Gonzáles vs. Perú, op. cit., párrs. 117, 119-120.

54 De acuerdo con el artículo 27.2, la Convención Americana "no autoriza la suspensión de los derechos determinados en los siguientes artículos: 3 (Derecho al Reconocimiento de la Personalidad Jurídica); 4 (Derecho a la Vida); 5 (Derecho a la Integridad Personal); 6 (Prohibición de la Esclavitud y Servidumbre); 9 (Principio de Legalidad y de Retroactividad); 12 (Libertad de Conciencia y de Religión); 17 (Protección a la Familia); 18 (Derecho al Nombre); 19 (Derechos del Niño); 20 
artículo 27.3 establece el deber de los Estados de informar inmediatamente a los demás Estados parte de la Convención, a través del Secretario General de la Organización de los Estados Americanos (OEA), "de las disposiciones cuya aplicación haya suspendido, de los motivos que hayan suscitado la suspensión y de la fecha en que haya dado por terminada tal suspensión". Concretamente, la Corte ha señalado que una situación de conflicto armado no exonera al Estado de sus obligaciones de respetar y garantizar los derechos de las personas, reconocidas en el artículo 1.1 de la Convención, y que, por el contrario, lo obliga "a actuar en manera concordante con dichas obligaciones" 55 .

\section{B. Las referencias extraconvencionales para fundamentar la remisión al $D I H$}

Pese a la posición sentada por la Corte Interamericana desde el año 2000, los Estados han continuado oponiendo excepciones preliminares que cuestionan la competencia de aquella para remitirse al DIH. En sus consideraciones para dar respuesta a dichos Estados, la Corte ha añadido referencias extraconvencionales que complementan la justificación para interpretar la Convención Americana a la luz de una rama del derecho ajena al corpus juris interamericano.

La remisión al artículo 29 de la Convención ha sido complementada con la referencia a las reglas generales de interpretación de los tratados recogidas en la Convención de Viena sobre el Derecho de los Tratados de 1969. Así, la Corte ha resaltado su competencia para interpretar la Convención Americana a la luz de otros tratados internacionales recordando que para la interpretación de un tratado "no sólo se toman en cuenta los acuerdos e instrumentos formalmente relacionados con éste" (art. 31.2 Convención de Viena), "sino también el sistema dentro del cual se inscribe" (art. 31.3 Convención de Viena). A partir de ello, la Corte ha indicado que "esta orientación tiene particular importancia para el [DIDH], que ha avanzado sustancialmente mediante la interpretación evolutiva de los instrumentos internacionales de protección". Según la Corte, "[e]stos parámetros [le] permiten [...] utilizar las normas del [DIH], ratificadas por el Estado demandado, para dar contenido y alcance a las normas de la Convención Americana" ${ }^{56}$.

Asimismo, no sólo sobre la base del artículo 27 de la Convención, sino también del artículo 3 común, el preámbulo y el artículo 4 PA II, y el artículo 75 PA I, la Corte ha hecho referencia expresa a la complementariedad o con-

(Derecho a la Nacionalidad), y 23 (Derechos Políticos), ni de las garantías judiciales indispensables para la protección de tales derechos".

55 Corte IDH. Caso Bámaca Velásquez vs. Guatemala. Fondo, op. cit., párr. 207, y Caso Cruz Sánchez y otros vs. Perú, op. cit., párr. 271.

56 Corte IDH. Caso Las Hermanas Serrano Cruz vs. El Salvador. Excepciones Preliminares, op. cit., párr. 119, y Caso Rodríguez Vera y otros (Desaparecidos del Palacio de Justicia) vs. Colombia, op . cit., párr. 39. 
vergencia entre el DIDH y el DIH y a la aplicabilidad del primero en tiempo de paz y durante un conflicto armado ${ }^{57}$. Según la Corte, la especificidad del DIH no impide la convergencia y la aplicación de las normas del DIDH consagradas en la Convención Americana y en otros tratados internacionales, reiterando así que el DiDH permanece en vigor durante un conflicto armado ${ }^{58}$. De esta manera, la Corte ha señalado que un Estado "no puede cuestionar la plena vigencia de los derechos humanos consagrados en la Convención Americana, con fundamento en la existencia de un conflicto armado de carácter no internacional" 59 .

Al respecto, la Corte ha precisado que al utilizar el DIH como norma de interpretación complementaria a la normativa convencional "no está asumiendo una jerarquización entre órdenes normativos, pues no está en duda la aplicabilidad y relevancia del DIH en situaciones de conflicto armado" ${ }^{60}$. La Corte también ha resaltado que dicha interpretación complementaria sólo implica que "puede observar las regulaciones del $\mathrm{DIH}$, en tanto normativa concreta en la materia, para dar aplicación más específica a la normativa convencional en la definición de los alcances de las obligaciones estatales" ${ }^{61}$. En ese sentido, la Corte ha reforzado el principio de la lex specialis afirmando que el DIH está mejor adaptado a los conflictos armados que el DIDH.

A mayor abundamiento, la Corte ha completado su razonamiento refiriéndose a la jurisprudencia de tribunales nacionales y a la legislación interna en materia de DIH. En un caso respecto del Estado de Colombia, la Corte declaró, remitiéndose al artículo 29.b de la Convención Americana, que las normas del DIH pertinentes para el análisis del caso (el artículo 3 común y el PA II) estaban en vigor en Colombia al momento de los hechos ${ }^{62}$. Además, la Corte señaló que, en la emblemática decisión de la Corte Constitucional de Colombia C-225 de $1995^{[63]}$, esas normas del DIH habían sido declaradas como "normas de jus cogens, que forman parte del 'bloque de constitucionalidad' colombiano y que son obligatorias" para el Estado y para todos los actores armados -estatales o no estatales- que participen en el conflicto armado. En consecuencia, la Corte reafirmó que las personas protegidas por el régimen

57 Corte IDH, Caso Las Hermanas Serrano Cruz vs. El Salvador. Excepciones Preliminares, op. cit., párrs. 114-116.

58 Ibíd., párrs. 111-113.

59 Ibíd., párr. 118.

60 Corte IDH. Caso Masacre de Santo Domingo vs. Colombia, op. cit., párr. 24, y Caso Rodríguez Vera y otros (Desaparecidos del Palacio de Justicia) vs. Colombia, op. cit., párr. 39.

61 Corte IDH. Caso Masacre de Santo Domingo vs. Colombia, op. cit., párr. 25, y Caso Rodríguez. Vera y otros (Desaparecidos del Palacio de Justicia) vs. Colombia, op. cit., párr. 39.

62 Ley 171 del 16 de diciembre de 1994, op. cit. Corte IDH. Caso de la "Masacre de Mapiripán” vs. Colombia. Fondo y Reparaciones, op . cit., párr. 115.

63 Corte Constitucional de Colombia, decisión C-225/95, op. cit., párrs. 30 y 35. 
del DIH "no pierden por ello los derechos o facultades que ya tengan conforme a la legislación del Estado bajo cuya jurisdicción se encuentran" ${ }^{4}$.

Además, en la línea de lo expuesto previamente, la Corte ha tenido la ocasión de complementar el argumento sobre su competencia para utilizar el DiH remitiéndose a los ya citados informes de las Comisiones de la Verdad (supra I.1.B). De esta manera, la Corte Interamericana ha hecho referencia a las afirmaciones de dichos informes sobre la pertinencia de la interpretación conjunta del DIDH y el DIH frente a un contexto de conflicto armado interno ${ }^{65}$.

Por tanto, constatamos que la Corte Interamericana, como órgano de control de derechos humanos, no ha recibido una habilitación expresa de la Convención Americana para utilizar el DIH en el marco de su competencia contenciosa. Sin embargo, una interpretación audaz de la misma y la remisión a fuentes extraconvencionales le han permitido justificar la posibilidad de interpretar dicha Convención a la luz de otros tratados, destacando en este caso los de DIH.

II. LA EVOLUCIÓN DE LAS REFERENCIAS EXPLÍCITAS AL DIH

EN LA JURISPRUDENCIA DE LA CORTE INTERAMERICANA

El reenvío explícito a las normas del DiH realizado por la Corte no tiene las mismas características a lo largo de su jurisprudencia. De una parte, hemos identificado una aproximación consistente en reforzar el contenido y alcances de los derechos humanos y de las obligaciones del Estado reconocidos en la Convención, a partir de interpretaciones a la luz del DIH (1). De otra parte, una aproximación que parece ir más allá de la simple interpretación de la Convención a la luz del DiH, puesta en evidencia a través de la utilización y declaración de violación de los principios básicos del DIH en el análisis de los hechos, y mediante la orden de medidas de reparación orientadas a la implementación del DIH (2).

\section{El DIH como complemento del contenido y alcance de los derechos y obligaciones reconocidos en la Convención Americana}

En el análisis de fondo de los casos vinculados a conflictos armados internos, la Corte ha examinado violaciones de derechos humanos y el incumplimiento de obligaciones estatales reconocidos en la Convención Americana en relación a normas de DIH. Así, la Corte ha complementado el contenido y alcance del derecho a la vida, del derecho a la integridad de la persona, del derecho a la

64 Corte IDH. Caso de la "Masacre de Mapiripán” vs. Colombia. Fondo y Reparaciones, op. cit., párr. 115.

65 Corte IDH. Caso Las Hermanas Serrano Cruzvs. El Salvador. Excepciones Preliminares, cit., párr. 117. 
libertad de la persona, del principio de legalidad, de los derechos del niño, del derecho a la propiedad privada, y del derecho de circulación y de residencia. Esta nueva interpretación a la luz del DIH ha generado una "relectura" de las respectivas obligaciones generales de los Estados parte de la Convención en el marco de un conflicto armado.

\section{A. Los derechos humanos convencionales a la luz del DIH}

Respecto al derecho a la vida (art. $4 \mathrm{CADH}$ ), citando a la Corte Internacional de Justicia y al Tribunal Europeo de Derechos Humanos (en adelante, TEDH) ${ }^{66}$, la Corte ha notado que el DIH no desplaza la aplicabilidad de dicho artículo, "sino que nutre la interpretación de la cláusula convencional que prohíbe la privación arbitraria de la vida" frente a hechos sucedidos en el marco y con ocasión de un conflicto armado (Cruz Sánchez y otros § 272). Asimismo, y en complemento con el derecho a la integridad de la persona (art. 5 CADH), la Corte ha recordado, como lo indica el artículo 3 común, que un Estado enfrentado a un conflicto armado interno "debe brindar a las personas que no participen directamente en las hostilidades o que hayan quedado fuera de combate por cualquier razón, un trato humano y sin distinción alguna de índole desfavorable", porque el DIH "prohíbe en cualquier tiempo y lugar los atentados a la vida y a la integridad personal" (Bámaca Velásquez § 207).

En los casos de masacres, en la determinación de la responsabilidad internacional del Estado, la Corte ha indicado que no puede obviar la existencia de deberes estatales generales y especiales de protección de la "población civil", derivados del artículo 3 común y los artículos 4 (Garantías fundamentales) y 13 (Protección de la población civil) PA II, que implican obligaciones pasivas (no matar, no violar la integridad física, etc.), así como positivas consistentes en impedir que terceros perpetren violaciones contra dichas personas (Masacre de Mapiripán § 114; Masacre de El Mozote $\S 148,153$ y 155).

Adicionalmente, la Corte ha recordado la prohibición absoluta e inderogable de la tortura y las penas o tratos crueles, inhumanos o degradantes "aún en las circunstancias más difíciles, tales como guerra, amenaza de guerra, lucha contra el terrorismo y cualesquiera otros delitos, estado de sitio o de emergencia, conmoción o conflicto interior, suspensión de garantías constitucionales, inestabilidad política interna u otras emergencias o calamidades públicas". Al respecto, la Corte se ha referido al artículo 3 común, al CG III (arts. 49, 52, 87, 89 y 97), al CG IV (arts. 40, 51, 95, 96, 100 y 119), al PA I

66 Corte Internacional de Justicia (CI), La legalidad de la amenaza o del empleo de armas nucleares, Opinión consultiva de 8 de julio de 1996, párr. 25, y Consecuencias jurídicas de la construcción de un muro en el territorio palestino ocupado, Opinión consultiva de 9 de julio de 2004, párr. 106-113. Asimismo, TEDH. Varnava y otros vs. Turquía [GS], sentencia de 18 de septiembre de 2009, párr. 185. 
(art. 75(2)(a)(ii)) y al PA II (art. 4(2)(a)) (J. § 304, Espinoza Gonzales § 141). Igualmente, citando la Norma 117 del DIH Consuetudinario, sistematizado por el Comité Internacional de la Cruz Roja $(\mathrm{CICR})^{67}$, la Corte ha establecido que la privación de la verdad a los familiares de víctimas de desaparición forzada en el contexto de un conflicto armado interno, el ocultamiento de información del Estado en el curso de procesos de transición que siguen a la firma de acuerdos de paz que ponen fin a un conflicto, así como la impunidad en las respectivas investigaciones, constituyen una violación del derecho a conocer la verdad de los familiares de las víctimas en violación de la integridad personal (Diario Militar $\S \S 295-302$ ).

El derecho a la libertad de la persona (art. $7 \mathrm{CADH})$ ha sido analizado a la luz del DIH en lo que concierne a la privación de la libertad como uno de los elementos concurrentes y constitutivos de la desaparición forzada (Osorio Rivera y familiares $\S 113$ ). Al respecto, la Corte se ha remitido a la Norma 99 del DIH Consuetudinario, según la cual "[q]ueda prohibida la privación arbitraria de la libertad". En consecuencia, la Corte ha señalado que conforme a las obligaciones que impone el derecho internacional, sobre todo el artículo 27.1 de la Convención, la prohibición de detención o encarcelamiento arbitrario no es susceptible de suspensión durante un conflicto armado no internacional (Osorio Rivera y familiares $\S 120$ ) y es aplicable inclusive en los casos en que se practique la detención por razones de seguridad pública (Desaparecidos del Palacio de Justicia § 402). Adicionalmente, aunque sin referirse de manera expresa al artículo 7 de la Convención, la Corte ha recordado que la toma de rehenes se encuentra prohibida "en cualquier tiempo y lugar", de acuerdo a lo señalado por el artículo 3 común y la Norma 96 del DIH Consuetudinario (Cruz Sánchez y otros § 269).

Sobre el principio de legalidad y de retroactividad (art. 9 CADH), la Corte se ha pronunciado de manera específica sobre la "penalización del acto médico" en el marco de un conflicto armado (De La Cruz Flores $\S \S 90-93$ ). Citando los artículos 16 PA I, 10 PA II y 18 CG I, la Corte consideró que el Estado cometió una violación del principio de legalidad, entre otras cosas, por haber penalizado el acto médico realizado por la víctima del caso que, según la Corte, "no sólo es un acto esencialmente lícito, sino que es un deber de[1] médico". La Corte también consideró que el Estado había violado dicho principio "por imponer a los médicos la obligación de denunciar posibles conductas delictivas de sus pacientes con base en la información que obtengan en el ejercicio de su profesión" (De La Cruz Flores § 102).

67 El CICR realizó una publicación sobre el DIH Consuetudinario aplicado a conflictos armados internacionales y conflictos armados no internacionales, como consecuencia de un estudio de la práctica del DIH en sentido amplio. CICR, El derecho internacional humanitario consuetudinario. Vol. I, HencKaerts, J.-M. y Doswald-Beck, L., eds. Cambridge: Cambridge University Press, 2007. 
Respecto a los derechos del niño (art. $19 \mathrm{CADH}$ ), la Corte ha establecido que el DIH "salvaguarda de forma general a las niñas y niños como parte de la población civil, esto es, de las personas que no participan activamente en las hostilidades, quienes deben recibir un trato humano y no ser objeto de ataque" (Rochac Hernández y otros § 110). En ese sentido, ha señalado que el contenido y el alcance de estos derechos en el contexto de conflictos armados no internacionales deben ser especificados teniendo en cuenta las disposiciones pertinentes de la Convención sobre los Derechos del Niño y del PA II, especialmente el artículo 4.3 de este, según el cual los niños deben recibir "los cuidados y la ayuda que necesiten" y, en particular, todas las medidas apropiadas para "preservar la unidad familiar y facilitar la búsqueda, identificación y reunificación [...] de las familias dispersas a causa de un conflicto armado y, en particular, de los niños no acompañados y separados" (Masacre de Mapiripán § 153, Masacre de las Dos Erres $\S 191$, Contreras y otros $\S \S 86$ y 107, Masacre de Santo Domingo $\S 238-239$, Rochac Hernández y otros $§ 110$ ).

Teniendo en cuenta el artículo 38.4 de la Convención sobre los Derechos del Niño, la Corte ha declarado que los niños, durante un conflicto armado, "se encuentran en una situación de mayor vulnerabilidad y riesgo de ver afectados sus derechos" (Contreras y otros $\S 108$, Masacres de El Mozote $\S 155$, Rochac Hernández y otros $\S 110$ ), provocando una "responsabilidad agravada" del Estado cuando estos son las víctimas del caso (Masacre de Mapiripán §§ 155-156, Masacres de Ituango § 246).

De otra parte, citando jurisprudencia precedente de un caso donde la referencia al DIH fue implícita ${ }^{68}$, la Corte se ha pronunciado sobre las violaciones de los derechos de las mujeres y niñas en el contexto de un conflicto armado. En ese sentido ha recordado que diversos órganos internacionales han reconocido que "durante los conflictos armados las mujeres y niñas enfrentan situaciones específicas de afectación a sus derechos humanos, como lo son los actos de violencia sexual, la cual en muchas ocasiones es utilizada como un medio simbólico para humillar a la parte contraria o como un medio de castigo y represión" derechos de las mujeres en un conflicto interno, además de afectarles a ellas de forma directa, puede tener el objetivo de causar un efecto en la sociedad a través de esas violaciones y dar un mensaje o lección"70 (Masacres de El Mozote § 165, Espinoza Gonzales § 226).

En lo que concierne al derecho a la propiedad privada (art. $21 \mathrm{CADH}$ ), frente a actos de robo de ganado y la destrucción con fuego de casas y tiendas de

68 Corte idh. Caso del Penal Miguel Castro Castro vs. Perú. Fondo, Reparaciones y Costas. Sentencia de 25 de noviembre de 2006. Serie C n. ${ }^{\circ} 160$.

69 Ibíd., párrs. 223-224.

70 Ibíd., párr. 224. 
caseríos pertenecientes a civiles, la Corte ha resaltado que los artículos 13 (Protección de la población civil) y 14 (Protección de los bienes indispensables para la supervivencia de la población civil) PA II prohíben, respectivamente, "los actos o amenazas de violencia cuya finalidad principal sea aterrorizar a la población civil", provocar un desplazamiento masivo de personas, así como "atacar, destruir, sustraer o inutilizar con ese fin los bienes indispensables para la supervivencia de la población civil" (Masacres de Ituango $\S 180$, Masacres de El Mozote § 179). La Corte ha remarcado la "especial gravedad" de esas violaciones (Masacres de Ituango § 182). Asimismo, ha interpretado el alcance del mismo derecho a la luz de las normas pertinentes del DIH Consuetudinario, en particular las normas 7, 8, 9 y 10, sobre la prohibición de los ataques contra bienes de carácter civil y la distinción entre estos últimos y los objetivos militares (Masacre de Santo Domingo $§ \$ 270$ 271, Operación Génesis § 349).

A mayor abundamiento, a propósito del pillaje cometido después de una masacre, la Corte ha señalado que tal acto, en tanto que toma de un bien en un conflicto armado sin el consentimiento de su propietario, está expresamente prohibido por el artículo 4.2.g PA II y la Norma 52 del DIH Consuetudinario (Masacre de Santo Domingo § 272). Igualmente, la Corte ha mencionado la Norma 133 del DIH Consuetudinario según la cual "[d]eberán respetarse los derechos de propiedad de las personas desplazadas" (Masacre de Santo Domingo § 272, Operación Génesis § 349).

En cuanto al derecho de circulación y de residencia (art. 22 CADH), la Corte ha citado el artículo 17 PA II que prohíbe ordenar el desplazamiento de la población civil "por razones relacionadas con el conflicto, a no ser que así lo exijan la seguridad de las personas civiles o razones militares imperiosas". Según dicho artículo 17, en este último caso "se tomarán todas las medidas posibles para que la población civil sea acogida en condiciones satisfactorias de alojamiento, salubridad, higiene, seguridad y alimentación" (Masacre de Mapiripán §§ 172-173, Masacres de Ituango § 209, Operación Génesis § 222). Así, la Corte ha hecho referencia a una "vulnerabilidad acentuada" en el caso de personas desplazadas (Masacres de Ituango $\$ \S 125.106$ y 212). Además, ha considerado que los Principios Rectores de los Desplazamientos Internos, elaborados por el Representante del Secretario General de la ONU para las Personas Desplazadas ${ }^{71}$, son particularmente pertinentes para definir el contenido y alcance del artículo 22 de la Convención Americana, ya que se fundan en normas del DIDH y del DIH (Masacre de Mapiripán $\$ 171$, Masacre de Ituango § 209, Masacre de Santo Domingo § 256, Operación Génesis $§ 222$ y 349).

71 ONU, Principios rectores relativos al desplazamiento de personas en el interior de su propio país, E/CN.4/1998/53/Add.2, de 11 de febrero de 1998. 


\section{B. Las obligaciones convencionales del Estado a la luz del DIH}

Como ha quedado en evidencia, la Corte Interamericana ha "redefinido" las obligaciones generales de los Estados parte de la Convención como consecuencia de la interpretación, a la luz del DIH, de los derechos humanos reconocidos en aquella. Sin embargo, adicionalmente, la Corte ha dado ciertas precisiones específicas referidas a dichas obligaciones generales de los Estados.

La obligación de respetar y garantizar los derechos (art. 1.1 CADH) y la de adoptar medidas de derecho interno (art. 2 CADH) han sido objeto de desarrollos recientes, poniendo énfasis en los límites a la posibilidad de concesión de amnistías vinculadas a un conflicto armado interno, haciendo una interpretación sistemática del artículo 6.5 PA II y la Norma 159 del DIH Consuetudinario. La Corte ha señalado que, según el DiH, en ocasiones, la emisión de leyes de amnistía al cese de las hostilidades en un conflicto armado no internacional se justifica para posibilitar el retorno a la paz. Sin embargo, ha precisado que la concesión de amnistías según el artículo 6.5 PA II no es absoluta, ya que existe también en DIH la obligación estatal de investigar y de juzgar los crímenes de guerra. Así, citando la Norma 159 del DIH Consuetudinario, la Corte ha resaltado que a pesar que "[c]uando hayan cesado las hostilidades, las autoridades en el poder se esforzarán por conceder la amnistía más amplia posible a quienes hayan participado en un conflicto armado no internacional o a las personas privadas de libertad por razones relacionadas con el conflicto armado", existe la excepción para el caso de las personas sospechosas, acusadas o condenadas por crímenes de guerra o crímenes de lesa humanidad, tal como dichas categorías han sido definidas en el Estatuto de Roma de la Corte Penal Internacional. Conforme al razonamiento de la Corte, dichas personas no podrán estar cubiertas por una amnistía (Masacres de El Mozote §§ 285-286).

Respecto a la obligación de investigar, juzgar y en su caso sancionar a los responsables de violaciones de derechos humanos (art. 1.1, en relación con los arts. 8 y $25 \mathrm{CADH}$ ), la Corte ha remarcado que el hecho de que la muerte de las víctimas se haya producido en el marco de un conflicto armado no internacional, no exime al Estado "de su obligación de iniciar una investigación, [...] aunque la Corte podrá tener en cuenta circunstancias o limitaciones específicas determinadas por la propia situación de conflicto al evaluar el cumplimiento por parte del Estado de sus obligaciones estatales" (Cruz Sánchez y otros § 350). Sobre el particular, la Corte ha sostenido que, "en el manejo de la escena de los hechos y el tratamiento de los cadáveres, deben realizarse las diligencias mínimas e indispensables para la conservación de los elementos de prueba y evidencias que puedan contribuir al éxito de la investigación". Así, a partir de los artículos 17, 20, 120 y 130 de los cuatro Convenios de Ginebra, respectivamente, el artículo 8 PA II y las Normas 112, 113, 115 y 116 del DIH Consuetudinario, la Corte ha advertido que, incluso 
en una situación de conflicto armado, el DIH "prevé obligaciones mínimas de debida diligencia relativas al correcto y adecuado levantamiento de cadáveres y los esfuerzos que deben adelantarse para su identificación o inhumación con el fin de facilitar su identificación posterior" (Desaparecidos del Palacio de Justicia § 496, Cruz Sánchez y otros § 367).

Adicionalmente, sobre la base de la Norma 117 del DIH Consuetudinario, la Corte ha recordado que los Estados deben "tomar [...] todas las medidas factibles para averiguar lo acaecido a las personas dadas por desaparecidas a raíz de un conflicto armado" y transmitir a los familiares de estas toda la información de que dispongan al respecto. De acuerdo con la Corte, esta obligación es independiente de que la desaparición de una persona sea consecuencia del ilícito de desaparición forzada propiamente o de otras circunstancias tales como su muerte en un operativo o errores en la entrega de los restos (Desaparecidos del Palacio de Justicia $§ 478$ ).

Compartimos con Hélène Tigroudja el eventual cuestionamiento al método de la Corte para utilizar el DIH, en la medida que puede suscitar reservas "quant à la rigueur avec laquelle ces emprunts sont opérés et leur pertinence"72. No obstante ello, la jurisprudencia desarrollada a través de los casos citados demuestra no solamente que la utilización conjunta del DIDH y el DIH en el razonamiento de la Corte es posible, sino también que tal utilización es deseable en la medida que la especificidad del DIH permite una mayor protección de los derechos humanos y una mayor exigencia a las obligaciones del Estado en el análisis de casos vinculados al contexto de un conflicto armado.

\section{El DIH integrado en el razonamiento de la Corte Interamericana}

La jurisprudencia de la Corte Interamericana da cuenta de otra aproximación en la utilización explícita del DIH que parece estar en los límites entre aplicación e interpretación, siendo esta última la única remisión "justificada" a dicho derecho, según la propia Corte. Esta utilización se ha caracterizado por ser más técnica y especializada, analizando los hechos de los casos desde los principios básicos del DiH e incluso declarando su violación o incumplimiento. De otra parte, en el marco de dicha aproximación, la jurisprudencia de la Corte ha incorporado el DIH -aunque de manera más aleatoria- en tanto que medida de reparación ordenada a los Estados declarados internacionalmente responsables, a fin de prevenir la repetición de actos contrarios a tal rama del derecho.

72 Tigroudja, H. La Cour interaméricaine des droits de l'homme au service de "l'humanisation du droit international public". Propos autour des récents arrêts et avis. 52 AFDI, 2006, 623-624. 


\section{A. Los principios del DIH puestos en escena}

A partir del año 2012, la Corte ha comenzado a indicar de manera anticipada y organizada que, conforme al artículo 29 de la Convención, considera "útil y apropiado" interpretar el contenido y alcance de las normas convencionales con las normas de DIH. En esa línea, la Corte ha señalado las fuentes del DIH a utilizar de manera complementaria como referente de interpretación, teniendo en cuenta su especificidad en la materia, a saber : i) los Convenios de Ginebra de 1949 -en particular el CG IV-; ii) el artículo 3 común; iii) el PA II, y iv) el DIH Consuetudinario (Masacres de El Mozote § 141, Masacre de Santo Domingo § 187, Operación Génesis § 221, Rochac Hernández y otros § 109).

Los indicios de una mayor integración del DIH en el razonamiento de la Corte han sido puestos en evidencia con la utilización de los principios fundamentales del DIH en el análisis de los casos Masacre de Santo Domingo, Operación Génesis y Cruz Sánchez y otros. Esto ha sido acompañado por la previa admisión de expertos en materia de DIH que ha contribuido a mejorar los conocimientos de la Corte sobre el DIH y la convergencia y complementariedad entre éste y el DIDH.

En el caso Masacre de Santo Domingo vs. Colombia, la CIDH y los representantes de las víctimas propusieron, en calidad de experto, al abogado colombiano Alejandro Valencia Villa, para declarar sobre temas específicos del DIH y, de manera transversal, sobre la convergencia y complementariedad de este y el DIDH. En la resolución de convocatoria a audiencia pública ${ }^{73}$, el presidente de la Corte estimó que el objeto del dictamen del perito "trasciende los intereses específicos de las partes en un proceso determinado, de modo tal que genera un interés relevante al orden público interamericano"74. Así, la Corte examinó por primera vez la responsabilidad del Estado por violaciones al derecho a la vida y a la integridad personal, interpretando la Convención Americana a la luz de los principios pertinentes del DIH, a saber, el principio de distinción, el principio de proporcionalidad y el principio de precaución $(\S 211)$.

El principio de distinción entre civiles y combatientes, y entre los bienes de carácter civil y los objetivos militares, ha sido definido por la Corte a partir de las normas del DIH, especialmente el artículo 3 común, el artículo 13.2 PA II y las Normas 1,7 y 87 del DIH Consuetudinario ( $\$ 212)$. Sobre esta base,

73 Corte IDH. Caso Masacre de Santo Domingo vs. Colombia. Resolución del Presidente de la Corte Interamericana de Derechos Humanos de 5 de junio de 2012, considerandos 22-23 y 26.

74 Según el artículo 35.1.f del Reglamento de la Corte, "la eventual designación de peritos" puede ser efectuada por la CIDH "cuando se afecte de manera relevante el orden público interamericano de los derechos humanos". Esta disposición hace de la designación de peritos por la CIDH una situación excepcional, sujeta a dicha condición. 
la Corte concluyó que, en el contexto de los enfrentamientos con las Fuerzas Armadas Revolucionarias de Colombia (FARC), el bombardeo sobre el caserío de Santo Domingo realizado por la Fuerza Aérea Colombiana constituyó un incumplimiento del Estado al principio de distinción en la conducción del operativo aéreo respectivo ( $\$ 213$ ). La Corte también citó las normas 11 y 12 del DiH Consuetudinario según las cuales están prohibidos los ataques indiscriminados, tales como "los que [...] emplean métodos o medios de combate cuyos efectos no sea posible limitar, como exige el [DIH]" (§ 234). La Corte constató además que los pilotos de la Fuerza Aérea Colombiana utilizaron sus ametralladoras en manifiesta despreocupación por la vida e integridad de las personas civiles que se desplazaban en las carreteras, en incumplimiento del principio de distinción (§ 235).

El principio de proporcionalidad ha sido definido por la Corte sobre la base de la Norma 14 del DIH Consuetudinario ( $\$ 214$ ). En el caso, la Corte señaló que el objetivo militar más general de la operación aérea habría sido la guerrilla presumiblemente ubicada en una "mata de monte" cerca del caserío de Santo Domingo. Sin embargo, la Corte consideró que no correspondía analizar el lanzamiento del dispositivo cluster "a la luz del principio de proporcionalidad, puesto que un análisis semejante implicaría determinar si los muertos y heridos entre la población civil pueden ser considerado[s] un resultado 'excesivo' en relación con la ventaja militar concreta y directa esperada en caso de haberse impactado un objetivo militar, lo cual no ocurrió en las circunstancias del caso" ( $\$ 215)$. De esta manera, para la Corte, el análisis sobre la base de criterios de proporcionalidad no devino pertinente porque esta ya había concluido un incumplimiento al principio de distinción por el hecho de que el bombardeo afectó directamente a la población civil. La Corte también constató que, "aun en la hipótesis de que pudiesen encontrarse guerrilleros entre la población civil, la ventaja militar que se buscaba obtener al atacar a un eventual combatiente adverso mezclado con población civil, no habría sido de tal índole que pudieran justificarse eventuales muertos o heridos civiles". De acuerdo con la Corte, "en esa hipótesis, esas acciones también habrían afectado el principio de proporcionalidad" (§ 235).

El principio de precaución ha sido definido a partir de las normas 15,17 y 18 del DIH Consuetudinario ( $\$ 216$ ). Sobre la base de las pruebas del expediente del caso, la Corte calificó la situación como contraria al principio de precaución, inter alia, porque el dispositivo cluster utilizado es un arma con precisión limitada, la instrucción del lanzamiento del dispositivo no fue precisa, los manuales y reglamentos vigentes para la época de los hechos indicaban que el dispositivo no podía ser utilizado en zonas pobladas o cerca de caseríos con población civil, unos minutos antes del lanzamiento del dispositivo ya se habían cometido errores con armas más precisas, la necesidad de utilizar ese tipo de arma en los enfrentamientos que tuvieron lugar había sido puesta en duda el día de los hechos, y porque las operaciones aéreas estuvieron desor- 
ganizadas al momento del lanzamiento del dispositivo. La Corte señaló que el expediente del caso no indicaba si en algún momento de las operaciones los pilotos habían tomado en cuenta que en las cercanías se encontraba un caserío poblado por civiles. Además, el expediente no precisaba si al tiempo de lanzar dispositivos cluster u otros cohetes se manifestó la necesidad de tener algún tipo de recaudo o precaución en relación con la seguridad de la población civil ( $\S$ 217-230). A mayor abundamiento, la Corte constató que los reglamentos y manuales de la Fuerza Aérea Colombiana vigentes al momento de los hechos establecían claramente que los ametrallamientos únicamente pueden tener lugar "en respuesta a ataques o tomas subversivas, cuando se tiene la certeza de no afectar a la población civil [y] por ningún motivo [...] en áreas pobladas o perimétricas". Así, la Corte declaró que el Estado también incumplió con el principio de precaución (§ 236).

Aproximadamente un año más tarde, la Corte reiteró su análisis sobre la base de los principios del DIH en otro caso, Operación Génesis vs. Colombia. En esta ocasión la CIDH, los representantes de las víctimas y el Estado propusieron, entre otros, los dictámenes de expertos en DIH. La CIDH propuso a la profesora peruana ElizABETH SALMÓn GÁrATE, los representantes de las víctimas al profesor español AlBerT GaLINSOGA y el Estado a la magistrada del Tribunal Superior Militar de Colombia María Paulina Leguizamón Zárate. Todos los expertos fueron propuestos para declarar sobre temas específicos del DIH vinculados al caso y sobre la convergencia y la complementariedad del DIDH y el DIH. En la resolución de convocatoria a audiencia pública ${ }^{75}$ el presidente de la Corte admitió, entre otros, los dictámenes de los tres expertos, reiterando que el objeto de los mismos generaba un interés relevante al "orden público interamericano" en el marco del análisis de un caso vinculado a un conflicto armado ( $\S 24-30)$.

Así, en lo que concierne al análisis de fondo del caso, por segunda vez, la Corte anunció la consideración de los principios relevantes del DIH "en la utilización de la fuerza en el marco de conflicto[s] armados de carácter no internacional" ( $\$ 222)$, en relación con alegadas violaciones del derecho a la vida y a la integridad personal por daños directos causados por bombardeos y ametrallamientos. La Corte consideró que "no ha[bían] sido presentadas evidencias que permitan concluir que los objetivos de los bombardeos de la Operación Génesis hayan incluido población o bienes de carácter civil" y que, en consecuencia, no podía concluir una violación del principio de distinción. A mayor abundamiento, la Corte estimó que no había sido demostrado que el Estado "estuviera impedido per se para llevar a cabo operaciones de contrainsurgencia en [el] territorio [concernido], salvo si el ataque a este objetivo

75 Corte IDH. Caso Marino López y otros (Operación Génesis) vs. Colombia. Resolución del Presidente de la Corte Interamericana de Derechos Humanos de 19 de diciembre de 2012, considerandos 21, 24, y punto resolutivo 1.B) 15 . 
hubiera implicado un ataque directo a poblaciones o bienes civiles lo cual, como [indicó], no se enc[ontraba] acreditado" (§ 239). Por tanto, la Corte no realizó el análisis correspondiente a los principios de proporcionalidad y precaución.

Recientemente, en el caso Cruz Sánchez y otros vs. Perú, la CIDH, los representantes de las víctimas y el Estado propusieron, entre otros, peritajes de expertos en DIH. La CIDH propuso al Relator Especial de las Naciones Unidas sobre Ejecuciones Extrajudiciales, Sumarias o Arbitrarias, Christof Heyns; los representantes de las víctimas, al abogado colombiano ALEJANDRo V aLENCIA Villa, y el Estado, al abogado peruano Jean Carlo Mejía Azuero. Los tres expertos fueron propuestos para declarar sobre temas específicos del DIH y, nuevamente, sobre la convergencia y complementariedad de este y el DIDH en el contexto de un conflicto armado no internacional. En la resolución de convocatoria a audiencia pública ${ }^{76}$ el presidente en ejercicio de la Corte admitió tales dictámenes estimando que podían contribuir a fortalecer las capacidades de protección del Sistema Interamericano en casos vinculados a un conflicto armado interno y la situación de las personas hors de combat, resaltando nuevamente el respectivo interés para el "orden público interamericano de los derechos humanos".

En el análisis de fondo del caso, la Corte consideró pertinente recurrir al corpus juris del DIH a fin de determinar el alcance de las obligaciones estatales de respeto y garantía para el derecho a la vida y el concepto de arbitrariedad que califica una privación de la misma, en situaciones de conflicto armado ( $\S 270$ y 273-274). Así, en cuanto al principio de distinción, la Corte hizo notar que si bien las víctimas del caso eran miembros de un grupo alzado en armas (el MRTA) y, por ende, no civiles, podían potencialmente ser beneficiarios de las salvaguardas contenidas en el artículo 3 común "siempre y cuando hubieran dejado de participar en las hostilidades y pudieran identificarse como hors de combat" al momento de la operación de rescate de los rehenes. Al respecto, de acuerdo con la Norma 47 del DIH Consuetudinario, el artículo 3 común, y citando el caso Bámaca Velásquez $z^{77}$ y jurisprudencia del $\mathrm{TEDH}^{78}$, la Corte resaltó que cualquier persona fuera de combate no puede ser objeto de ataque y, en esa medida, el Estado debe brindarle un trato humano y sin distinción alguna de índole desfavorable ( $§$ 276-278). Dicho esto, la Corte precisó que la controversia del caso no giraba en torno a la necesidad, proporcionalidad y precaución en el uso de la fuerza, sino en determinar si las víctimas fallecieron como consecuencia de actos de agentes estatales

76 Corte IDH. Caso Cruz Sánchez y otros vs. Perú. Resolución del Presidente en Ejercicio de la Corte Interamericana de Derechos Humanos de 19 de diciembre de 2013, considerandos 20,54 y 66 .

77 Corte IDH. Caso Bámaca Velásquez vs. Guatemala. Fondo, cit., párr. 207

78 TEDH. Varnava y otros vs. Turquía, cit., párr. 185. 
una vez que se encontraban fuera de combate en términos del DiH o si, por el contrario, murieron cuando tomaban parte activa en las hostilidades ( $\$ 287$ ). Concretamente, para la Corte, el Estado no proporcionó una explicación verosímil y satisfactoria sobre la forma en la que Eduardo Cruz Sánchez falleció en una zona bajo el control exclusivo del Estado como consecuencia de un disparo realizado cuando el cuerpo permanecía casi inmóvil, en una situación de hors de combat, concluyendo así que se trató de una ejecución extrajudicial (§§ 316-319) ${ }^{79}$.

\section{B. El DIH incorporado en las medidas de reparación ordenadas por la Corte Interamericana}

Entre las diferentes sentencias citadas en las que la Corte ha utilizado el DIH de manera explícita, ciertas medidas de reparación ordenadas se refieren directamente a dicha rama del derecho en tanto que consecuencia de la declaración de la responsabilidad internacional del Estado. Asimismo, en los casos Myrna Mack Chang vs. Guatemala ${ }^{80}$ y Masacre de La Rochela vs. Colombia ${ }^{81}$, la Corte ha integrado el DIH en las medidas de reparación, a pesar de no haberlo empleado en el análisis sobre el fondo. Tales medidas de reparación responden básicamente a "garantías de no repetición", esto es, medidas tendientes a que no vuelvan a ocurrir violaciones al $\mathrm{DIH}^{82}$, consistentes en la adopción de medidas de derecho interno y en la formación de agentes públicos.

Sobre las medidas de derecho interno, en la sentencia de reparaciones en el caso Bámaca Velásquez, y en respuesta a la demanda específica de la CIDH y los representantes de las víctimas ( $\S$ 69.d-70.e), la Corte consideró que Guatemala debía adoptar medidas de derecho interno conforme al artículo 2 de la Convención (Deber de Adoptar Disposiciones de Derecho Interno). Precisamente, la CIDH demandó que "los procedimientos utilizados por las fuerzas militares en relación con el trato de los combatientes capturados" sean adaptados a las normas de DIDH y DIH para garantizar sus derechos, ya que la víctima del caso era miembro de un grupo alzado en armas. La Corte ordenó a Guatemala adoptar "las medidas legislativas y de cualquier otra

79 Respecto a las dos otras presuntas víctimas involucradas, la Corte concluyó que su muerte se produjo cuando aún se encontraba en curso el operativo y la evacuación de rehenes, y que no contaba con prueba variada y suficiente que las pudiera calificar como hors de combat. Por lo tanto, consideró que no podía afirmar que la actuación del Estado frente a estas "hubiera configurado una privación arbitraria de la vida derivada de un uso de armas letales en forma contraria a los principios del [DIH] aplicables". Corte IDH. Caso Cruz Sánchez y otros vs. Perú, cit., párrs. 339-343.

80 Corte IDH. Caso Myrna Mack Chang vs. Guatemala, cit.

81 Corte IDH. Caso de la Masacre de La Rochela vs. Colombia. Fondo, Reparaciones y Costas. Sentencia de 11 de mayo de 2007. Serie C n. ${ }^{\circ} 163$.

82 Corte IDH. Informe Anual 2012, 19-20. 
índole necesarias" para adecuar el ordenamiento jurídico guatemalteco a las normas internacionales de derechos humanos y de DiH, así como "para darles efectividad en el ámbito interno" (§ 85).

Asimismo, en la sentencia del caso de las Masacres de El Mozote, tratándose de violaciones graves a derechos humanos, y en consideración del carácter continuado o permanente de la desaparición forzada cuyos efectos no cesan mientras no se establezca la suerte o paradero de las víctimas y su identidad sea determinada, la Corte ordenó al Estado abstenerse de recurrir a figuras como la amnistía u otra disposición análoga para excusarse de la obligación de investigar. En ese sentido, la Corte ordenó al Estado asegurar que la Ley de Amnistía General para la Consolidación de la Paz no pueda continuar representando un obstáculo para la investigación, identificación, juzgamiento y sanción de responsables de los hechos del caso, "ni pued[a] tener igual o similar impacto respecto de otros casos de graves violaciones de derechos humanos reconocidos en la Convención Americana que puedan haber ocurrido durante el conflicto armado en El Salvador" (Masacres de El Mozote $\S \S 296$ y 318). Por tanto, la Corte declaró que su pronunciamiento sobre la Ley de Amnistía en El Salvador tenía efectos generales.

En cuanto a la formación de agentes públicos, en la medida que las violaciones de derechos humanos fueron perpetradas por paramilitares actuando con la colaboración, tolerancia o aquiescencia del Estado, o directamente por agentes estatales, la Corte ha ordenado que el Estado adopte medidas tendientes a formar y capacitar a todos los miembros de sus cuerpos armados, de policía y de sus organismos de seguridad sobre los principios y normas de derechos humanos -aun bajo los estados de excepción-y del DIH (Myrna Mack Chang § 282, Masacre de Mapiripán § 316, Masacres de Ituango § 409, Masacre de las Dos Erres § 251, Osorio Rivera y familiares § 274). Según la Corte, para responder a esta medida, el Estado debe implementar, en un plazo razonable y con la asignación presupuestaria respectiva, programas permanentes y obligatorios de educación en derechos humanos y DIH en las fuerzas armadas a todos los niveles jerárquicos (Masacre de Mapiripán $\S$ 316, Masacres de Ituango § 409). La Corte ha precisado que una mención especial de la respectiva sentencia de la Corte y de los instrumentos internacionales de derechos humanos y de DIH deberá ser hecha como parte de dichos programas (Masacre de Mapiripán § 317, Masacre de La Rochela § 303, Masacre de las Dos Erres $§ 251)$.

En el caso de la formación de funcionarios, especialmente jueces y fiscales, es particularmente importante el impacto de las medidas ordenadas por la Corte Interamericana en materia de DIH. Ciertamente, según la Corte, cuando un Estado es parte en un tratado internacional como la Convención Americana, todos sus órganos, incluidos sus jueces, los diferentes órganos vinculados a la administración de justicia en todos los niveles y, en general, toda autoridad pública están en la obligación de ejercer ex officio un "control 
de convencionalidad" entre las normas y prácticas internas y la Convención Americana, en el marco de sus respectivas competencias y de las regulaciones procesales correspondientes. En esta tarea, las autoridades concernidas deben tener en cuenta no solamente el tratado, sino también la interpretación que del mismo ha hecho la Corte interamericana, intérprete última de la Convención Americana ${ }^{83}$. De esta manera, en los casos que corresponda, tales autoridades públicas, en ejercicio del "control de convencionalidad”, tendrán la obligación de leer la Convención tal como esta ha sido interpretada a la luz del DIH, para evitar que un caso que involucre a su Estado sea sometido al Sistema Interamericano, o que dicho Estado reincida en la comisión de un acto generador de responsabilidad internacional.

A la luz de lo expuesto, compartimos con el juez Jean-Paul Costa y Michael O'Boyle que la utilización de los principios del DiH “will not be an easy job for a Court of Human Rights since it will require distinctions to be made between combatants and civilians -not always a straightforward task". Además, "[i]t will also require that the principle of proportionality be applied by balancing military advantage against the duty to protect civilian life. Thus the Court would have to determine whether the military gains of a particular operation justified the risks of civilian casualties" ${ }^{84}$. En el caso de la Corte Interamericana, tal utilización obliga a reflexionar sobre el rol y evolución a futuro del DIH en su jurisprudencia, teniendo en cuenta que la referencia a los principios del DiH y la eventual declaración de su violación o incumplimiento parecen ubicar a la Corte en la frontera de la interpretación y la aplicación de dicho derecho ${ }^{85}$. A ello se suma que, pese a que la Corte no puede aplicar el DIH ni declarar la responsabilidad del Estado por las violaciones al mismo, aquella se permite, en una lógica preventiva, ordenar medidas de reparación que lo involucran. Ya que las reparaciones constituyen consecuencias directas de la declaración de la responsabilidad internacional del Estado concernido, podemos preguntarnos si, al ordenar tales medidas, la Corte no excede el marco de sus competencias, actuando como un verdadero órgano de control del DIH. Esta pregunta toma toda la relevancia cuando constatamos que la propia Corte Interamericana tiene a cargo la supervisión del cumplimiento de las medidas de reparación que ordena.

83 Corte iDH. Caso Almonacid Arellano y otros vs. Chile. Excepciones Preliminares, Fondo, Reparaciones y Costas. Sentencia de 26 de septiembre de 2006. Serie C n. ${ }^{\circ} 154$, párrs. 123-124, y J.vs.Perú, cit., párr. 407.

84 Costa y O’Boyle, cit., 118.

85 Ver SALMÓN, E. Institutional approach between IHL and IHRL: Current Trends in the jurisprudence of the Inter-American Court of Human Rights. Journal of International Humanitarian Legal Studies. Vol. 5, n. ${ }^{\circ} 1-2,2014,152-185$. 
CONCLUSIÓN

La Corte Interamericana ha devenido un mecanismo indirecto de control del DIH. Como tal, se ha atribuido el derecho de verificar el cumplimiento de las obligaciones derivadas del DiH por un Estado parte de la Convención Americana, antes, durante y después de un conflicto armado interno, para declarar, de ser el caso, las violaciones de derechos humanos y el incumplimiento de las obligaciones estatales reconocidos en dicha Convención.

Las dinámicas de los últimos casos vinculados a situaciones de conflicto armado, en particular Masacre de Santo Domingo, Operación Génesis y Cruz Sánchez y otros, demostrarían una vocación de especialización de la Corte Interamericana respecto al DIH. En efecto, la Corte ha admitido dictámenes de expertos en la materia, ha declarado que el alcance del DIH y su convergencia con el DIDH es un asunto de interés para el orden público interamericano, ha concluido que la utilización del DIH es "útil y pertinente" incorporando el DIH Consuetudinario, y ha formulado sus consideraciones desde el análisis de los principios básicos de dicha rama del derecho. Todos éstos indicios de una decisión de "prise au sérieux"

El futuro de la jurisprudencia interamericana en la materia se torna entonces del mayor interés. Como ya ha sido señalado, la utilización del DIH por la Corte Interamericana se encuentra en un punto de no retorno, y la evolución de esta utilización reafirma una contribución al desarrollo del DIH, asegurando su respeto.

\section{BIBLIOGRAFÍA}

Aivo, GÉRARD. Convergences entre droit international humanitaire et droit international des droits de l'homme: vers une assimilation des deux corps de règles? Revue trimestrielle des droits de l'homme. Año 21, n. ${ }^{\circ} 82,1$ de abril de 2010, 341-370.

Aponte, Alejandro. El sistema interamericano y el derecho internacional humanitario: una relación problemática. En ElSNER, GisELA (ed.), Sistema interamericano de protección de los derechos humanos y derecho penal internacional. Uruguay: Fundación Konrad Adenauer, 2010, 125-170.

Burgorgue-Larsen, Laurence y Úbeda de Torres, Amaya. War in the Jurisprudence of the Inter-American Court of Human Rights. En Human Rights Quarterly. Vol. 33(1), February 2011, 148-174.

Cerna, Cristina. The History of the Inter-American System's Jurisprudence as Regards Situations of Armed Conflict. 2 International Humanitarian Legal Studies, 2011, 3-52.

86 Decaux, E. De l'imprévisibilité de la jurisprudence européenne en matière de droit humanitaire: Cour européenne des droits de l'homme (Gde Ch.), Kononov c. Lettonie, 17 mai 2010. RTDH, año 22, n. ${ }^{\circ} 86,1$ de abril de 2011, 357. 
Costa, Jean Paul y O’Boyle, Michael. The European Court of Human Rights and International Humanitarian Law. En La Convention européenne des droits de l'homme, un instrument vivant / The European Convention on Human Rights a Living Instrument, Mélanges en l'honneur de / Essays in Honour of Christos L. Rozakis. Bruxelles: Bruylant, 2011, 107-129.

Decaux, Emmanuel. De l'imprévisibilité de la jurisprudence européenne en matière de droit humanitaire: Cour européenne des droits de l'homme (Gde Ch.), Kononov c. Lettonie, 17 mai 2010. Revue trimestrielle des droits de l'homme. Año 22, n. ${ }^{\circ}$ 86, 1 de abril de 2011, 343-357.

Flauss, Jean-François (dir.). Les nouvelles frontières du droit international humanitaire. Actes du colloque du 12 avril 2002 organisé par l'Institut d'études de droit international de l’Université de Lausanne. Bruxelles: Nemesis-Bruylant, 2003.

FRANCO, LEONARDO. Interpretación y aplicabilidad del derecho internacional humanitario por la Corte Interamericana de Derechos Humanos. En CICR, Estudios de derecho internacional humanitario consuetudinario. Memorias del evento de presentación. Bogotá: CICR, 2009, 63-81.

Hervieu, Nicolas. La jurisprudence européenne sur les opérations militaires à l'épreuve du feu. La Revue des droits de l'homme [en línea], Actualités Droits-Libertés, <http:// revdh.revues.org/890> (consultada el 15 de diciembre de 2015).

Marmin, Sébastien. Les organes de contrôle du droit international des droits de l'homme et le droit international humanitaire. Revue trimestrielle des droits de l'homme. Año 23, n. ${ }^{\circ} 92,1$ de octubre de 2012, 815-836.

Martin, FAnNy. Application du droit international humanitaire par la Cour interaméricaine des droits de l'homme. Revue internationale de la Croix-Rouge. Vol. 83, n. ${ }^{\circ} 844$, diciembre de 2001, 1037-1066.

Salmón, Elizabeth. "Institutional approach between inl and IhrL: Current Trends in the jurisprudence of the Inter-American Court of Human Rights". Journal of International Humanitarian Legal Studies. Vol. 5, n. ${ }^{\circ}$ 1-2, 2014, 152-185.

Sassòli, Marco. "La Cour européenne des Droits de l'Homme et les conflits armés". En: Droits de l'homme, démocratie et état de droit : liber amicorum Luzius Wildhaber. Zürich: Dike, 2007, 709-731.

Tigroudja, Hélène. "La Cour interaméricaine des droits de l'homme au service de 'l'humanisation du droit international public'. Propos autour des récents arrêts et avis". 52 Annuaire Français de Droit International, 2006, 617-640.

Valencia, Alejandro. "La interacción y convergencia entre el derecho internacional humanitario y el derecho internacional de los derechos humanos". En Memorias Segundo Curso Internacional Especializado en Derechos Humanos del Instituto Colombiano de Derechos Humanos. Medellín: ICDH, 2014, 217-238. 